\title{
Para uma análise argumentativa da temporalidade: o exemplo de quando ${ }^{1}$
}

\author{
Pour une analyse argumentative de la temporalité: l'exemple de quand \\ Marion Carel \\ Ecole des Hautes Etudes en Sciences Sociales - Paris - França
}

$\diamond$

\begin{abstract}
Resumo: Fiéis aos estudos que fundamentaram a Teoria da Argumentação na Língua dos quais elas todas saíram, as teorias argumentativas do sentido interessaram-se essencialmente pelas conjunções chamadas lógicas (mas, no entanto, ...) e pelo léxico. Nenhum, ou poucos trabalhos, sobre a temporalidade. Notar-se-á, nesse sentido, que o artigo de Ducrot sobre o imperfeito (DUCROT, 1979) não se inscreve no contexto da Argumentação na Língua. Na sequência de Lescano e de seu estudo sobre agora (LESCANO, 2012), propomo-nos a explorar o campo da temporalidade, interessando-nos pela conjunção quando. Afirmaremos, após uma análise dos empregos temporais antepostos de "quando", no primeiro dos três contos de Flaubert, que a datação não é um fenômeno linguístico central.
\end{abstract}

Palavras-chave: Quando anteposto; Temporalidade; Argumentação na língua; Datação

Résumé: Fidèles aux études qui ont fondé la théorie de l'Argumentation dans la Langue, les théories argumentatives du sens se sont essentiellement intéressées aux conjonctions dites logiques (mais, pourtant, ...) et au lexique. Pas, ou peu de travaux sur la temporalité. On notera dans ce sens que l'article de Ducrot sur l'imparfait (DUCROT, 1979) ne s'inscrit pas dans le cadre de la théorie de l'Argumentation dans la Langue. A la suite de Lescano et de son étude de maintenant (LESCANO, 2012), on se propose d'explorer le champ de la temporalité en s'intéressant à la conjonction quand. On soutiendra après une analyse des emplois temporels antéposés de "quand" dans le premier des trois contes de Flaubert que la datation n'est pas un phénomène linguistique central.

Mots-clés: Quand antéposé; Temporalité; Argumentation dans la langue; Datation

\section{Introdução}

Fiéis aos estudos que fundamentaram a Teoria da Argumentação na Língua, dos quais todas elas se originaram, as teorias argumentativas do sentido (penso na Teoria dos Estereótipos de Anscombre, na Semântica dos Possíveis Argumentativos de Galatanu, ou ainda na Teoria dos Blocos Semânticos de que se tratará aqui) interessaram-se especialmente pelas conjunções chamadas lógicas (mas, no entanto, ...) e pelo léxico. Nenhum, ou poucos trabalhos sobre a temporalidade. Notar-se-á nesse sentido, que o artigo de Ducrot sobre o imperfeito (DUCROT, 1979) não se inscreve no quadro da teoria da Argumentação na Língua. Seguindo Lescano e seu estudo sobre agora (LESCANO, 2012), eu me proponho explorar o campo da temporalidade, interessando-me pela conjunção quando.
Insisto no fato de que são os empregos mais temporais de quando que vão me interessar, empregos aos quais concorda-se geralmente em dar a função semântica de denotar a data do acontecimento descrito na oração principal (seria o caso de (1) ou uma data anterior à do acontecimento descrito na oração principal (seria o caso de (2)):

(1) quando Pedro entrou, uma porta bateu. emprego de quando que assinalaria a simultaneidade

(2) quand Pierre fut entré, il posa son sac ${ }^{2}$ emprego de quando que assinalaria a anterioridade

- ver, por exemplo (BORILLO, 1988), (VOGELEER, 1998), (LE DRAOULEC, 2006) ou (BENZITOUN, 2013).

\footnotetext{
1 Tradução: Leci Borges Barbisan - PPG Letras - PUCRS.

2 Em português: Pedro já tinha entrado quando ele largou a pasta.
} 
O estudo desses empregos será conduzido no contexto da Teoria dos Blocos Semânticos (TBS), segundo a qual um papel central deve ser dado, na constituição da significação, aos encadeamentos de orações por uma conjunção da família de portanto (encadeamentos normativos) e aos encadeamentos de orações por uma conjunção da família de no entanto (encadeamentos transgressivos): todo enunciado, segundo a TBS, é parafraseável por encadeamentos normativos ou transgressivos, encadeamentos que constituem o que eu denomino "encadeamentos argumentativos". Tratar-se-á, portanto, de mostrar que é possível reduzir o emprego "temporal" de quando a um conjunto de encadeamentos normativos ou transgressivos, assim como é possível reduzir os discursos de mas a tal conjunto. As indicações temporais constituem apenas efeitos de sentido, decorrentes de uma organização argumentativa primeira.

Mais precisamente, eu me interessarei pelos empregos antepostos de quando, dentre os quais se encontram também empregos menos temporais como (3):

(3) quando fazia bom tempo, Pedro ia à floresta emprego denominado "semi-causal" de quando.

Se tais empregos de quando parecem mais claramente argumentativos, eles criam, entretanto, um problema para a TBS, porque a interpretação causal não é obrigatória. A temporalidade fornece um modo de explicar isso: (3) constataria a coincidência repetida do bom tempo e a saída de Pedro, e essa repetição tornaria possível a interpretação causal, sem impô-la. Como uma semântica argumentativa pode fazer essa distinção entre uma ordem, digamos pré-causal, e uma ordem causal? Será necessário, é claro, responder também a essa pergunta.

Meu artigo terá três partes, correspondendo a cada um dos tipos de emprego provindos da abordagem temporal: o emprego que assinalaria a coincidência, o emprego que assinalaria a anterioridade e o emprego semi-causal. A discussão será conduzida com exemplos do primeiro dos Três contos de Flaubert, "Um coração simples", texto que, por sua qualidade literária, garante a riqueza dos empregos. Para cada exemplo, a análise temporal clássica será substituída por uma análise argumentativa.

Esse projeto, admito, assemelha-se um pouco a um desafio esportivo. Trata-se, de fato, de utilizar uma teoria, a Teoria dos Blocos Semânticos, construída a partir do estudo de conectores de aparência lógica como mas, e de termos avaliativos como corajoso, e de aplicálo a um domínio descritivo e objetivo que não é o dele, mas que diz respeito a uma característica temporal dos acontecimentos, a simultaneidade. Espero, entretanto, mostrar, nos exemplos que apresentarei, que a abordagem clássica encontra, de fato, dificuldades e que a abordagem argumentativa permite evitá-las. A datação dos acontecimentos não é um fenômeno linguístico central.

\section{O emprego de "quando" considerado ter como característica semântica a de marcar a coincidência temporal de dois acontecimentos}

\section{1 Êxitos e dificuldades da abordagem temporal}

O exemplo que me interessará tem lugar no início da quarta parte de "Um coração simples". Virginie, a menina da casa onde Félicité trabalha como empregada, e Victor, seu sobrinho marinheiro, ambos morreram, e foi ao papagaio Loulou que a empregada agora se apegou. É dele e dela que se trata:

\section{Exemplo A}

O senhor Paul, um dia, teve a imprudência de lhe assoprar nas narinas a fumaça de um charuto; uma outra vez em que a senhora Lormeau o irritava com a ponta de sua sombrinha, ele agarrou o cabo; enfim, ele se perdeu.

Ela o tinha colocado na grama para refrescá-lo um minuto; e, quando ela voltou, não havia mais papagaio! Primeiramente, ela o procurou entre os arbustos, na beira do riacho e nos telhados, sem ouvir sua dona que lhe gritava: - "Tome cuidado! Você é maluca!" A seguir ...

Eu deixarei de lado a descrição do papel da subordinada no conjunto da construção textual (é a subordinada em quando que abre a cena da busca enlouquecida e a opõe à calma anterior? Trata-se, como no emprego de primeiramente colocado no início da frase seguinte, daquilo que Charolles (1995) chama um introdutor de contexto?), para me concentrar nos elos entre a subordinada com quando e a oração principal de que ela depende gramaticalmente. É, de fato, para descrever o elo entre essas duas orações que se recorre à noção de simultaneidade temporal.

O exemplo (A) constituiria um caso do mesmo tipo de (1) quando Pedro entrou, uma porta bateu: o desaparecimento do papagaio seria declarado como tendo acontecido ao mesmo tempo que o retorno de Félicité. Mais precisamente, a ocorrência de nenhum papagaio significaria, no texto de Flaubert, um acontecimento - e não um estado - e o enunciado de Flaubert seria equivalente a uma formulação como quando ela voltou, não havia mais papagaio. Certamente, a forma gramatical quando ela voltou, não havia mais papagaio estaria mais de acordo com os hábitos, mas o imperfeito da 
oração principal, associado ao pretérito perfeito simples da subordinada, faria da ausência do papagaio uma circunstância do retorno de Félicité. Ora, não é esse o sentido do enunciado de Flaubert, que confronta o retorno de Félicité a outro acontecimento: a ausência do papagaio acontece no momento do retorno de Félicité e a surpreende.

De inspiração fregeana (FREGE, 1892/1971), essa análise temporal consegue explicar claramente por que a proposição subordinada e a proposição principal constituem semanticamente um todo: a proposição subordinada seria o nome próprio de um instante e, ternário, o predicado Estar Ausente se aplicaria ao mesmo tempo a Loulou, ao lugar em que ele se encontrava e enfim ao valor temporal determinado pela subordinada introduzida por quando. As duas orações gramaticais de (A) constituiriam, desse modo, uma única oração semântica.

A causa desse êxito é, no entanto, ao mesmo tempo a razão das dificuldades da abordagem temporal clássica. Porque, admitindo-se que a subordinada sirva somente para datar o acontecimento de que se trata na principal, não se compreende por que é possível inserir no exemplo (A) outro complemento de tempo sem, com isso, produzir redundância:

Ela se ausentou e, cinco minutos mais tarde, quando ela voltou, não havia mais papagaio!

Do mesmo modo, se deveria poder substituir a subordinada por qualquer outro nome da mesma data, de modo que (A) deveria ser equivalente ao enunciado (4):

(4) "Ela se ausentou e, cinco minutos mais tarde, não havia mais papagaio!"

Ora, alguma coisa de (A) desapareceu em (4), não somente, é claro, a respeito de Félicité (não é mais comunicado que ela voltou), mas igualmente a respeito do papagaio. Há, do enunciado (A) ao enunciado (4), uma mudança de ponto de vista: é Félicité que constata a ausência do papagaio em (A), enquanto que, em (4), trata-se do ponto de vista do narrador. Além disso, essa mudança de ponto de vista é acompanhada por uma mudança de definição do lugar onde Félicité deixou o papagaio. Félicité é descrita por Flaubert como não tendo encontrado o papagaio, de modo que, paralelamente, o papagaio é descrito como tendo abandonado seu lugar, ou melhor, o que Félicité considerava como sendo o seu lugar. Não há nada de tudo isso em (4): é apenas dito que o papagaio mudou de lugar, sem que mais nada seja comunicado a respeito do lugar. Assim, substituir a subordinada de quando pela locução cinco minutos mais tarde leva a uma reviravolta na construção do sentido da principal. A subordinada de quando de (A) não serve apenas para datar o acontecimento de que se trata na principal. Ela influencia a própria compreensão desse acontecimento: o não havia mais papagaio de Flaubert significa que o papagaio deixou o lugar que Félicité pensava ser o dele.

Pode-se multiplicar os exemplos:

(5) Quando o tempo estava claro, ia-se cedo para a fazenda de Geffosses. O pátio era inclinado, a casa no meio; e o mar ao longe aparece como uma mancha cinzenta. Félicité retirava de sua sacola fatias de carne fria, e se almoçava numa peça que continuava a leitaria. (Flaubert, "Um coração simples")

O exemplo (5) aparece no início da segunda parte do conto. Félicité acaba de ser recrutada pela senhora Aubain, e o texto desenvolve os hábitos da casa no interior de parágrafos respectivamente introduzidos pelas expressões todas as quintas-feiras, cada segundafeira de manhã, em épocas indeterminadas, e enfim aqui, quando o tempo estava claro. Além de estruturar o texto, a subordinada em quando constitui com a principal uma proposição geral. A presença de cedo na principal impede, no entanto, qualquer leitura causal: o tempo claro não é a razão do horário das partidas. A abordagem temporal clássica descreveria (5) como (A). A alusão à claridade do tempo teria como função semântica denotar um conjunto de dias que a variável temporal do verbo ir-se embora tomaria então como valores. (5) só comunicaria, desse modo, uma oração cujo verbo seria ir-se embora, o sujeito indeterminado se só comunicaria, desse modo, uma única proposição cujo verbo seria ir-se embora, o sujeito gramatical se, e os complementos cedo, para a fazenda de Geffosses e enfim quando o tempo estava claro. A subordinada indicaria as partidas, sem explicá-las.

Por real que seja o êxito do resultado anterior, tal análise encontra, entretanto, eu o anunciava, as mesmas dificuldades que a análise proposta para (A). Por que, por exemplo, não se pode substituir a subordinada de (5) por qualquer outro nome dos mesmos dias? Por que (5) não é equivalente ao enunciado (6) ou ao enunciado (7)?

(6) "todos os dias primeiro do mês, ia-se bem cedo à fazenda de Geffosses"

(7) "regularmente ia-se cedo para a fazenda de Geffosses"

De fato, de acordo com (5), a família vai a Geffosses para passear, fazer piquenique, aproveitar o tempo bom. Ora, não há nada disso em (6) ou em (7), que possa pertencer a uma narrativa do aumento dos aluguéis nas fazendas da senhora Aubain. A subordinada de (5), como a de (A), não se limita, portanto, a datar o acontecimento descrito pela principal - ou ainda a assinalar um ponto 
de vista (cf. VOGELEER, 1998): ela influencia a própria natureza do acontecimento; o ia-se bem cedo à fazenda de Geffosses de Flaubert significa que ia-se bem cedo para aproveitar o bom tempo.

A abordagem temporal clássica é, portanto, insuficiente. Além de uma eventual capacidade de datar, as subordinadas do exemplo (A) ou do exemplo (5) têm outra função. A proximidade que a conjunção quando estabelece entre os conteúdos das duas proposições é mais forte do que uma simples coincidência de datas entre acontecimentos. Eu me proponho a descrever esse elo forte no quadro da semântica argumentativa. Ver-se-á então que a construção argumentativa permite prever a simultaneidade dos acontecimentos descritos pela proposição subordinada e pela proposição principal: ela não se acrescenta à construção temporal clássica; ela a substitui.

\subsection{Análise argumentativa do enunciado (A) quando ela voltou, nada de papagaio!}

A descrição do exemplo (A) será feita em dois tempos. Será primeiramente descrito, neste parágrafo, o sentido do exemplo (A) - ou, para ser exata, o sentido que atribuo a (A); depois será descrito, no parágrafo seguinte, o papel de quando na construção desse sentido - esse papel é o mesmo, qualquer que seja a leitura que se faça de (A).

De modo geral - é a interpretação que eu manterei -, o enunciado (A) quando ela voltou, nada de papagaio significa que Félicité não encontrou Loulou. $\mathrm{O}$ acontecimento é descrito por fragmentos - Félicité volta, o papagaio não está mais lá - e a confrontação desses fragmentos, sua colocação juntos no interior de uma única cena, de um único acontecimento, pela conjunção quando, leva a compreender que Félicité não encontrou Loulou. Não que seja dito que Félicité não encontrou Loulou: as duas orações ela voltou e nada de papagaio comunicam apenas dois dos conteúdos que seriam comunicados por ela não encontrou o papagaio. Mas a conjunção quando impõe considerar esses dois conteúdos como as facetas de um mesmo Acontecimento e o significado de ela não o encontrou pode representar o papel desse Acontecimento.

Mais tecnicamente, a proposição complexa comunica os dois conteúdos argumentativos seguintes, respectivamente expressos pela oração principal e pela oração subordinada:

ASSUMIDO: o papagaio estava ali antes de sua partida no entanto ele não estava ali na sua volta, entendido como concretizando Y ESTAVA ANTES ONDE X PENSA SER O LUGAR DE Y PT NEG Y ESTÁ NO LUGAR QUE X PENSA SER O LUGAR DE Y;
EVOCADO: ela voltou no entanto ela não o encontrou, entendido como concretizando X ESTÁ NO LUGAR QUE X PENSA SER O LUGAR DE Y PT NEG X ENCONTRA Y.

Os termos técnicos "assumido" e "evocado" são uma retomada das noções que Ducrot (1972) designava com os termos "posto" e "pressuposto". Eles descrevem de fato a função dos conteúdos na organização geral do texto de acordo com a "lei de encadeamento" de Ducrot. Os elementos "assumidos" são articulados uns aos outros e constituem o tecido principal do texto; os elementos "evocados" podem ter diversos papeis, como participar da coesão geral do texto ou completar semanticamente o conteúdo assumido - um estudo preciso desses diversos papeis levaria seguramente a abandonar a noção global de "evocado" em benefício de noções particulares que correspondem a cada um desses papeis. O emprego de quando assinala que o conteúdo evocado completa semanticamente o conteúdo assumido.

Além disso, se terá notado que os conteúdos argumentativos assumidos e evocados pelo enunciado (A) são duplos, constituídos ao mesmo tempo por um encadeamento argumentativo e por um esquema "concretizado" pelo encadeamento, cujo nome aparece em maiúsculas. A tradição lógica interpreta esses esquemas, quando se trata de encadeamentos normativos, como garantias dos encadeamentos (o encadeamento a leitura do livro era difícil portanto Maria não o comprou seria garantido, por exemplo, pela crença INÚTIL DC NEG COMPRA). Tal interpretação é, entretanto, impossível no quadro da TBS que põe em paralelo os encadeamentos normativos e os encadeamentos transgressivos - seria absurdo falar do "responsável" por um encadeamento em no entanto. Por isso, os esquemas argumentativos são interpretados pela TBS como os modelos, ou ainda as formas, dos encadeamentos: o técnico é "aspecto argumentativo", mas, para não arriscar a introduzir confusão com a noção de aspecto utilizada nos estudos clássicos dos tempos gramaticais, eu falarei, neste artigo, de "esquema" argumentativo. $\mathrm{O}$ encadeamento argumentativo representa assim o que há de anedótico na realidade descrita (o enunciado (A) diz respeito por exemplo a Félicité e a Loulou), enquanto o esquema argumentativo representa a natureza da realidade descrita. Em nossa descrição do exemplo (A), é assim o esquema argumentativo do conteúdo afirmado que explicita que o não havia mais papagaio de Flaubert significa que o papagaio abandonou o lugar que Félicité pensava ser o dele. É o esquema argumentativo do conteúdo evocado que explicita que o ela voltou de Flaubert significa que ela voltou ao lugar que ela pensava ser o do papagaio. Notemos enfim que encadeamento e esquema são evidentemente ambos 
dados pelo enunciado como relativos à mesma realidade: o encadeamento "concretiza" o esquema argumentativo.

Como o emprego de quando participou dessa construção argumentativa?

\subsection{Descrição do emprego coesivo de quando}

Propõe-se substituir a hipótese temporal, segundo a qual as duas proposições ligadas pelo emprego de quando em (A) significariam dois acontecimentos com mesma data, pela hipótese, argumentativa, de que as duas orações gramaticais têm como conteúdos duas facetas de um mesmo Acontecimento que se pode designar linguisticamente. Trata-se, é claro, de precisar essas noções de "faceta de Acontecimento" e de "Acontecimento que se pode designar linguisticamente". Tudo o que está em questão, é claro, é precisar essas noções de "faceta Acontecimento" e de Acontecimento linguisticamente designável". Eu me inspirarei, para isso, na noção de "traço semântico", do qual eu manterei duas características: de um lado, o fato de que os traços semânticos são acrescentados no interior da significação para constituir uma única propriedade: por outro lado, o fato de que os traços semânticos constituem precisamente os traços de um termo da língua.

Comecemos pela capacidade de significação dos termos de fundir os diversos elementos semânticos que a constituem. Utilizar uma palavra da língua em um discurso não consiste em enunciar, de modo aleatório, seus diversos traços: pedaços, de certo modo, de um mesmo Predicado, eles aparecem como um todo no momento da enunciação. A significação argumentativa das próprias palavras tem a mesma propriedade. Tomemos o adjetivo corajoso. Sua significação comporta vários esquemas, dentre os quais PENOSO PT FAZ e BEM DC FAZ: o enunciado Pedro foi corajoso ao intervir na reunião significa ao mesmo tempo que não era fácil intervir e que Pedro interveio com razão - de modo que, se se tivesse querido comunicar que a intervenção era árdua e ao mesmo tempo inútil, teria sido necessário utilizar a conjunção mas e dizer Pedro foi corajoso ao intervir, mas foi inútil. Ora, apesar dessa pluralidade de conteúdos, o enunciado Pedro foi corajoso ao intervir no momento da reunião aparece como um julgamento único. Com o emprego da palavra corajoso, os conteúdos argumentativos intervir era penoso no entanto Pedro interveio (entendido como concretizando PENOSO PT FAZ) e era preciso intervir portanto Pedro fez (entendido como concretizando BEM DC FAZ) aparecem como duas "facetas de um mesmo Acontecimento". Os esquemas argumentativos são fundidos pelo próprio emprego da palavra corajoso: eles são apresentados como ligados a um mesmo Predicado.
Essa capacidade dos nomes e dos adjetivos de aparecerem semanticamente unidos, essa operação linguística, interior às próprias palavras e não apenas às suas ocorrências, e que consiste em reunir a diversidade dos esquemas argumentativos inscritos em suas significações, essa operação é igualmente realizável por conjunções. É o caso de certos empregos de mas, como mostra a comparação de (9) e de (10) - imaginar-se-á que Maria, que chegou no Morvan, telefone para Pedro, que ficou em Paris:

(9) "faz tempo bom, mas está frio"

(10) "faz tempo bom mas frio"

Enquanto (9) acrescenta a um primeiro julgamento sobre o tempo uma argumentação do tipo faz frio portanto não vou sair e dá assim um sentimento de concessão, ao contrário, (10) constrói um único julgamento: o valor "quente", inscrito na significação de fazer bom tempo, é eliminado em benefício do valor "frio" que, acrescentado e fundido com outros valores de fazer bom tempo, constrói um novo termo fazer bom tempo mas frio. Os esquemas são apresentados por (10) como relacionados a um mesmo Predicado.

Minha primeira hipótese será que o emprego de quando em (A) tem a mesma capacidade de fundir-se: os dois conteúdos argumentativos, respectivamente comunicados pelas duas proposições gramaticais, são dados pela conjunção quando como duas características de um mesmo Acontecimento; os dois esquemas argumentativos X ESTÁ NO LUGAR QUE X PENSA SER O LUGAR DE Y PT NEG X ENCONTRA Y P ESTAVA ANTERIORMENTE NO QUE X PENSA SER O LUGAR DE Y PT NEG Y ESTÁ NO LUGAR QUE $X$ PENSA SER O LUGAR DE Y são declarados relacionarem-se ao mesmo Predicado. Essa primeira hipótese explica a unidade da proposição complexa.

Minha segunda hipótese amplificará o parentesco que as proposições complexas com quando mantêm com as proposições simples. Trata-se-á de dizer que, não somente o emprego de quando funde em um único Predicado os esquemas argumentativos comunicados (primeira hipótese), mas, além disso, que ele impõe que esse Predicado tenha um substantivo (segunda hipótese). É o caso do emprego de quando em (A) cujas proposições exprimem esquemas argumentativos pertencentes ambos à significação de não encontrar. Compreende-se assim por que (A) significa, a grosso modo, que Félicité não encontrou Loulou - os conteúdos argumentativos de (A) constituem dois dos conteúdos comunicados por ela não encontrou o papagaio. Compreende-se igualmente por que cada oração de (A) influencia a interpretação da outra, já que a instrução é dada ao interpretante que encontre um termo único significando ao mesmo tempo o esquema 
argumentativo da subordinada e o esquema argumentativo da principal.

Eu sintetizarei essas duas hipóteses dizendo que um emprego de quando é "coesivo" quando a conjunção dá a instrução de interpretar as duas orações gramaticais que ela relaciona por meio de dois conteúdos argumentativos cujos esquemas pertencem à significação de um mesmo termo. É o caso do emprego de quando em (A). As proposições "ela voltou" e "nada de papagaio" são interpretadas como duas facetas do Acontecimento ela não o encontrou: elas não significam dois Acontecimentos cujas datas seriam idênticas; elas significam dois fragmentos de um único Acontecimento. É igualmente o caso do emprego de quando em (5) "quando o tempo estava claro, ia-se cedo à fazenda de Geffosses":

ASSUMIDO: ia-se certos dias cedo à fazenda de Geffosses e portanto se aproveitava do lugar, entendido como concretizando o esquema DESLOCAR-SE PARA APROVEITAR O EXTERIOR DC APROVEITAR O EXTERIOR;

EVOCADO: se o tempo estava claro, aproveitava-se da fazenda de Geffosses, entendido como concretizando o esquema BOM TEMPO DC APROVEITAR DO EXTERIOR

Os esquemas dos dois conteúdos pertencem ambos à significação de aproveitar do exterior.

Essa descrição argumentativa tem uma consequência. Ela permite, eu o anunciava, prever a interpretação temporal de (A). Como facetas de um mesmo Acontecimento, os fragmentos das duas proposições significam que compartilham, por esse fato, a data do Acontecimento e aparecem, desse modo, como simultâneos.

Em resumo, o emprego coesivo de quando não efetua um simples acréscimo, ponderado, do conteúdo da oração principal e do conteúdo da subordinada. Contrariamente ao que é defendido pela descrição clássica, de inspiração fregeana, também não constitui, graças às duas orações gramaticais, um conteúdo simples. Ao modo dos marcadores discursivos, ele "articula" os dois segmentos impondo interpretá-los de modo que seus conteúdos concretizem esquemas que provêm da significação de uma mesma expressão. A temporalidade da subordinada é só um efeito de sentido produzido pelas leituras realistas da construção argumentativa.

\section{O emprego de quando tido como marcador de anterioridade do acontecimento descrito pela subordinada em relação ao acontecimento descrito pela principal}

A abordagem temporal não distingue fundamentalmente a estrutura de (2) quando Pedro já tinha entrado, ele largou a pasta; e (1) quando Pedro entrou, uma porta bateu: de novo, a oração complexa exprimiria um único julgamento cujo predicado seria fornecido pelo verbo da oração principal e, de novo, o valor temporal desse predicado seria estabelecido por comparação com o instante que a oração subordinada indicaria. A diferença estaria na relação de comparação; enquanto em (1), o bater da porta era declarado concomitante à entrada de Pedro, em (2) o largar a pasta seria declarado posterior à entrada de Pedro.

Vamos ver, ao inverso, que a estrutura argumentativa do emprego de quando realizada por (2) é muito diferente daquela do emprego coesivo de quando, realizado por (1): não são mais dois conteúdos fundidos, mas um único conteúdo argumentativo que aqui é comunicado. Eu falarei de emprego unitário de quando.

\subsection{Dificuldade da abordagem temporal}

O exemplo que vai me interessar constitui a primeira frase da parte III. Félicité está instalada na família. Paul, filho da senhora Aubain, acaba de partir e Félicité coloca toda sua afeição em Virginie. Eu tomo a última frase da parte II e a primeira frase, com quando, da parte III:

\section{Exemplo B}

Mas uma ocupação veio distraí-la; desde o Natal, ela levou todos os dias a menina ao catecismo.

Ela já tinha feito, na porta, uma genuflexão, quando ela avançava sob a nave alta entre a linha dupla de cadeiras, abria o banco da senhora Aubain, sentava-se, e passava os olhos em torno dela. (Ver EXEMPLO B - p. 4)

(11) “depois que ela já tinha feito, na porta, uma genuflexão, ela avançava sob a nave alta..."

Do mesmo modo para (12) e (13), que retomam no passé antérieur ${ }^{3}$ e no passé simple, os exemplos (B) e (11):

(12) "quando ela tinha feito, na porta, uma genuflexão, ela avançou sob a nave alta"

(13) “depois que ela fez, na porta, uma genuflexão, ela avançou sob a nave alta" e o mesmo ainda para (14) e (15), fabricados a partir de (12) e (13) substituindo o grupo verbal "fazer uma genuflexão" por um grupo verbal, "falar com Jean", que não tem nenhum elo cultural com a entrada na igreja:

\footnotetext{
O passé antérieur, em francês, é um tempo composto, construído com os verbos être (ser ou estar) ou avoir (ter ou haver) no passé simple (nosso pretérito perfeito é o correspondente mais próximo do passé simple francês) e indica uma ação anterior a outra ação do passado. Não há passé antérieur em português. Nossa língua emprega o imperfeito do verbo auxiliar, não o pretérito perfeito, como o francês. Em vista disso, os exemplos 12 e 13 receberam essas traduções em português. (NT)
} 
(14) “quando já tinha falado com Jean, Marie avançou sob a nave alta"

(15) “depois que já tinha falado com Jean, Marie avançou sob a nave alta"

Ora, há entre (14) e (15) uma diferença. É que (14) faz da conversa com Jean um preâmbulo para a entrada. $\mathrm{O}$ fim da conversa não é a causa da entrada, mas a conversa devia ter acabado, ter atingido seu objetivo, para que Maria pudesse avançar. Em (15), por outro lado, essa correlação desaparece: depois que isola as duas ações, que são declaradas independentes.

Dá-se o mesmo com (12) e (13). Certamente a genuflexão é, para os católicos, preâmbulo à entrada em uma igreja, assim de modo semelhante (13), como (12), descreve as etapas de um processo. Mas isso é dito linguisticamente por (12) e apenas subentendido por (13). Basta que se substitua uma genuflexão por duas genuflexões, e o fenômeno aparecerá claramente: quando apresenta sempre as genuflexões como preâmbulo para a entrada, enquanto depois que separa esse acontecimento daquele da entrada. Dá-se o mesmo com (B) e (11). É claro que é difícil imaginar que o personagem de (11), regularmente, faz preceder por acaso sua entrada, por uma genuflexão, de modo que a genuflexão parece preliminar necessária à entrada. Mas isso é um subentendido do caráter repetido da sequência genuflexão-entrada. O exemplo de Flaubert impõe, ao contrário, por sua própria significação, que o acontecimento descrito pela subordinada seja preâmbulo para o descrito pela principal, sem que haja necessidade de levar em conta o caráter repetido da sequência, nem de levar em conta práticas católicas. Ora, dessa diferença, a abordagem clássica não dá conta: ela não permite distinguir (14) de (15), (12) de (13), nem enfim (11) de (B); ela não permite distinguir quando e depois que.

O problema, em suas grandes linhas, se parece assim com o problema encontrado quando do estudo do exemplo (A). A abordagem temporal clássica é insuficiente. Certamente, a genuflexão de Félicité é anterior à sua entrada: certamente, a indicação sobre as datas, tal como a abordagem clássica prevê, é verdadeira. Mas essa relação temporal não permite prever que a genuflexão, que é declarada em (B), seja um preâmbulo. É essa dificuldade da abordagem temporal que eu proponho atenuar substituindo a descrição clássica de (B) por uma descrição argumentativa. O emprego de quando liga os acontecimentos descritos pela subordinada e a principal mais fortemente do que apenas por suas datas.

\subsection{Análise argumentativa do exemplo (B)}

Como a descrição de (A), a descrição de (B) será feita em dois tempos: eu descreverei primeiramente o sentido que dou a (B), para isolar a seguir o papel de quando na construção desse sentido.

Minha hipótese é que a oração complexa (B) comunica um único conteúdo argumentativo:

ASSUMIDO: ela obtinha com uma genuflexão o direito de entrar e portanto ela avançava sob a alta nave entre a dupla linha das cadeiras, compreendido como concretizando o esquema TÉRMINO DE UM PREÂMBULO PARA ENTRAR COMO CATÓLICA DC ENTRAR COMO CATÓLICA.

O esquema argumentativo descreve a natureza do acontecimento. A entrada na igreja se faz, não uma vez que o movimento de genuflexão terminou no tempo, mas uma vez que, "acabada", a genuflexão atingiu seu objetivo, o de obter o direito de entrar. Notar-se-á igualmente que o termo "genuflexão" não aparece no esquema argumentativo, mas apenas no encadeamento: a genuflexão é um meio circunstancial de permitir a entrada; é como preâmbulo que ela conduz à entrada. Além disso, eu fiz a escolha interpretativa de dizer que não se trata, em (B), de um simples deslocamento para o interior, mas de uma entrada como católico. Sob a interpretação que eu adoto, a natureza do hábito descrito por (B) é assim diferente da natureza do acontecimento descrito por (16):

(16) quando ele já tinha tocado a campainha, o inspetor de polícia abriu a porta e entrou e que se reduz a ACABAMENTO DE UM PREÂMBULO PARA ENTRAR DC ENTRAR. Enfim, o encadeamento argumentativo evocado por (B) liga pela conjunção portanto (uma reformulação de) a oração subordinada (uma reformulação de) à oração principal.

Pode-se fazer uma análise paralela do exemplo (17):

(17) Ela the forneceu roupa, tratou de limpar seu alojamento, sonhava em estabelecê-lo na padaria, sem que ele perturbasse a senhora. Quando a ferida se abriu, ela fez curativos todos os dias, algumas vezes lhe trazia bolo, colocava-o ao sol em cima de uma maço de palha.

Trata-se aí dos cuidados que Félicité dá ao pai Colmiche nesse período transitório em que, separada pela morte, de Virginie e de Victor, Félicité ainda não se voltou para o papagaio Loulou (fim da parte III). De novo, o acontecimento descrito na principal (a dedicação de Félicité a Colmiche) é apresentado como tendo tido um precedente, alusão que desaparece em (18) e em (19), respectivamente, obtidos a partir de (17) substituindo quando por depois que e substituindo o passé antérieur por um passé simple: 
(18) "depois que a ferida se abriu, ela fez curativos todos os dias"

(19) "quando a ferida se abriu, ela fez curativos todos os dias"

(18) isola os dois acontecimentos que são o aparecimento da ferida e o curativo, e, ao inverso, (19) - se não é compreendido como um emprego coesivo de quando - descreve a abertura da ferida como a razão dos curativos: nem um, nem outro descreve os curativos de Félicité como tendo tido preâmbulo. Só (17) comunica:

ASSUMIR: a ferida por sua abertura tornou-se passivel de curativo portanto ela fez curativo todos os dias, entendido como concretizando o esquema TÉRMINO DE UM PREÂMBULO PARA FAZER CURATIVO FAZER CURATIVO.

Outras interpretações de (B) ou de (17) são possíveis. Pode-se ainda entender que Félicité entra na igreja como simples acompanhante de Virginie - o fim da frase "e passava os olhos em torno dela" seria um argumento para essa interpretação: a genuflexão seria então o equivalente a uma campainha e o esquema expresso por (B) seria ACABAMENTO DE UM PREÂMBULO PARA ENTRAR PORTANTO ENTRAR. Do mesmo modo, pode-se reinterpretar (17) apoiando-se no fato de que esse enunciado é introduzido no texto de Flaubert pelo enunciado "a bondade de seu coração se desenvolveu" e pode, portanto, exprimir ACABAMENTO DE UM PREÂMBULO PARA FAZER O BEM DC FAZER O BEM. Em todos os casos, entretanto, os esquemas argumentativos seriam do mesmo tipo: ligado a dois tempos gramaticais correlacionados (mais-que-perfeito e imperfeito, passé antérieur e passé simple,...), o emprego anteposto de quando impõe a construção de um único conteúdo argumentativo tendo como esquema ACABAMENTO DE UM PREÂMBULO PARA FAZER Q DC FAZER Q.

\subsection{Descrição do emprego unitário de quando}

Um passo deve ser feito para distinguir o papel de quando do papel dos tempos gramaticais nessa família de exemplos. Eu direi que o emprego de quando é unitário quando é construído um único conteúdo argumentativo e, no interior desse conteúdo, um encadeamento argumentativo constituído pela oração subordinada seguida pela oração principal; o emprego unitário de quando não impõe, por outro lado, o esquema argumentativo.
Minha hipótese será que (B) realiza um emprego unitário de quando e que o tipo do esquema argumentativo dos exemplos como (B) é imposto pelo equilíbrio dos tempos gramaticais. Não que esse equilíbrio de tempos imponha, sozinho, o esquema argumentativo TÉRMINO DE UM PREÂMBULO PARA FAZER Q DC FAZER Q: vimos que, relacionadas por depois que, as duas orações o tumor se abriu e ela fez curativo todos os dias não são suficientes para comunicar TÉRMINO DE UM PREÂMBULO PARA FAZER CURATIVO DC FAZER CURATIVO. Mas a anterioridade que as formas verbais compostas indicam em relação a suas formas simples correlacionadas, essa anterioridade de que Benveniste diz que ela "não reflete uma relação cronológica que seria colocada na realidade objetiva" (BENVENISTE, 1966, p. 247), essa anterioridade toma, quando ela é expressa no interior de um conteúdo argumentativo único, a forma ACABAMENTO DE UM PREÂMBULO PARA FAZER Q DC FAZER Q. O emprego da conjunção quando em (B) impõe a unicidade do conteúdo argumentativo e, nesse contexto, é o equilíbrio dos tempos gramaticais que impõe o esquema argumentativo ACABAMENTO DE UM PREÂMBULO PARA FAZER Q DC FAZER Q.

É esse elo forte, estabelecido pelo esquema argumentativo entre o acontecimento ao qual faz alusão a oração subordinada e o acontecimento ao qual faz alusão a principal, que está na origem da interpretação temporal dos enunciados de quando da família de (B). Como estrutura do encadeamento que o concretiza, o esquema ACABAMENTO DE UM PREÂMBULO PARA ENTRAR COMO CATÓLICO DC ENTRAR COMO CATÓLICO apresenta, descreve, diz que a genuflexão à qual (B) faz alusão é um "preâmbulo" para o avanço sob a nave alta. Temporalmente interpretada, a noção de preâmbulo torna-se uma relação de anterioridade cronológica. A análise temporal decorre do próprio sentido do esquema argumentativo - daquilo que a TBS chama seu "bloco semântico".

Em resumo, a ocorrência de quando no exemplo (B) tem uma função diferente daquela que ela tinha no exemplo (A). Enquanto no emprego coesivo, ela levava a somente associar o conteúdo argumentativo expresso pela subordinada e o conteúdo argumentativo expresso pela principal, a conjunção quando conduz, em emprego unitário, à construção de um único conteúdo argumentativo, cujo encadeamento liga argumentativamente a subordinada e a principal e cujo esquema argumentativo é livre. Os tempos gramaticais de (B) impõem a seguir, nesse contexto argumentativo, um esquema do tipo ACABAMENTO DE UM PREÂMBULO PARA FAZER Q DC FAZER Q, esquema cujo próprio sentido prevê a leitura temporal clássica. 


\section{O emprego de quando, conhecido marcador de uma semi-causalidade}

O emprego semi-causal de que se vai tratar agora constitui, como (B), um emprego unitário de quando: ele impõe a construção de um único conteúdo argumentativo; ele impõe que o encadeamento evocado seja constituído pela oração subordinada seguida pela oração principal; e ele não impõe o esquema argumentativo. Essa indiferença ao esquema argumentativo distingue o emprego unitário de quando dos operadores causais. Será visto igualmente nesse quadro que o esquema argumentativo pode ser declarado não expresso pelo texto, e enfim que ele pode ser transgressivo.

\subsection{Dificuldade da abordagem temporal}

Eu me interessarei pelo exemplo (C):

\section{Exemplo (C)}

a bondade de seu coração se desenvolveu. Quando ela ouvia na rua os tambores de um regimento em marcha, ela se punha diante da porta com uma jarra de cidra, e oferecia a beber aos soldados. Ela tratou dos doentes de cólera. Ela protegia os Poloneses e até mesmo houve um que declarava querer desposá-la.

O exemplo (C) aparece no final da terceira parte: ele precede imediatamente o episódio do pai Colmiche. De acordo com a abordagem temporal, sua significação é construída do mesmo modo que a de (5) "Quando o tempo estava claro, ia-se cedo à fazenda de Geffosses": a subordinada de (C) denotaria momentos - aqueles em que Félicité ouve tambores - e, binário, o predicado significado por meio de "por-se diante de sua porta" seria aplicado, de um lado a Félicité, de outro lado e a esses momentos. Como a descrição temporal de (5), essa descrição temporal de (C) tem êxito - ela explica a unidade semântica da proposição complexa - e a contrapartida negativa desse êxito: ela não chega a explicar por que a substituição da subordinada por outro nome dos mesmos momentos (por exemplo, "todas as quartas-feiras") muda o sentido de (5). Além disso, e é o que me interessará aqui, ela impede de prever a semi-causalidade de (C). Pode-se certamente defender que o locutor de $(\mathrm{C})$ assinala uma repetição de coincidências e que a interpretação causal é inferida dessa repetição. Mas, para ser possível, essa inferência exige que $(\mathrm{C})$ comunique que os momentos nos quais Félicité ouviu os tambores dos regimentos são precisamente aqueles das saídas com cidra. Ora, esse elemento está ausente da descrição temporal de (C) que se reduz à aplicação do predicado "pôr-se diante de sua porta", a Félicité e a certo número de valores temporais.
Acrescentá-lo é decidir-se a perder a unidade semântica de $(\mathrm{C})$.

Além disso, há exemplos semi-causais de quando que fazem alusão a uma única coincidência, de modo que a pluralidade das coincidências não parece estar na origem da semi-causalidade dos exemplos:

(20) Passo a passo, e as mãos juntas, elas iam para o altar todo iluminado, ajoelhavam-se no primeiro degrau, recebiam a hóstia a seguir, e na mesma ordem voltavam a seu local de oração. Quando foi a vez de Virginie, Félicité inclinou-se para vê-la; e com a imaginação que as verdadeiras ternuras dão, pareceu-lhe que ela própria era essa criança; seu rosto tornava-se o dela, seu vestido a vestia, seu coração batia no peito dela; no momento de abrir a boca, fechando os olhos, só lhe faltou desmaiar. (FLAUBERT, “Um coração simples")

A passagem descreve a primeira comunhão de Virginie. Diferentemente do enunciado em porque (21):

\section{(21) Félicité inclinou-se porque era a vez de Virginie}

o enunciado (20) com quando não é causal. A vez de Virginie é, para Félicité, uma ocasião de compartilhar da vida da menina, não a causa imediata de seu movimento. Mas a vez de Virginie não constitui por isso a simples data do movimento de Félicité. Inclinando-se, essa última reage ao fato de que é a vez de Virginie: a substituição de quando foi a vez de Virginie por às seis horas ou quando o padre tossiu mudaria o sentido de (20). É preciso encontrar um intermediário entre a causalidade, forte demais, e a temporalidade, fraca demais.

\subsection{Análise argumentativa dos exemplos}

Eu levantarei a hipótese de que (20) realiza um emprego unitário de quando. Um único conteúdo argumentativo é comunicado, encadeando a oração subordinada e a oração principal:

ASSUMIDO: foi a vez de Virginie portanto Félicité se inclinou, entendido como concretizando o esquema HÁ OCASIÃO DE PARTICIPAR DC Y FAZ ESFORÇO PARA PARTICIPAR.

A natureza do acontecimento, isto é, o esquema concretizado pelo encadeamento, não é, por outro lado, imposto por quando. Ela é aqui determinada pelo grupo verbal da proposição principal (inclinar-se para vê-la indica ao mesmo tempo um esforço - inclinar-se - e um objetivo - vê-la, participar de sua vida), mas, em outros exemplos, ela é descrita por termos exteriores ao texto 
à proposição complexa de quando. É o caso do exemplo (C):

ASSUMIDO: Se ela ouvia na rua os tambores de um regimento em marcha, então ela se punha diante da porta com uma jarra de cidra, entendido como concretizando PERCEBER SOFRIMENTO DC CONSOLAR.

Trata-se de novo de um emprego unitário de quando. Um único conteúdo argumentativo é construído, cujo encadeamento liga a subordinada à principal, mas cujo esquema, não descrito por quando, provém, desta vez, da significação argumentativa do termo bondade: introduzido textualmente por a bondade de seu coração se desenvolveu, (C) deve ser lido como um exemplo de bondade, um esforço para atenuar o sofrimento do outro.

A dupla determinação do conteúdo argumentativo, pelo enunciado de quando e pelo texto, instaura às vezes um deslocamento entre as palavras do encadeamento, entrelaçadas por quando, e o esquema argumentativo: no encadeamento evocado por (C), trata-se de ouvir os tambores e de se pôr diante da porta com cidra; no esquema, trata-se de perceber um sofrimento e de reconfortar. Esse deslocamento tem aqui um efeito de leve zombaria - seria forte demais falar de ironia, porque Flaubert tem simpatia por Félicité. O comportamento de Félicité parece exagerado. Não pelo fato de levar cidra para os soldados - o jornal de agosto de 1914 de Lucien Jacques, publicado em Les carnets de Moleskine, conta comportamentos semelhantes:

Deixemos Marchéville às 6 horas da manhã. Passemos por Maizeray... Buzy vilarejo rico, onde os habitantes recebem a tropa com copos de água fresca alegrada com absinto... Saint-Jean-les-Buzy... outros ainda. Marcha interminável, em ziguezague.

O entusiasmo um pouco exuberante de Félicité transparece no fato de que ela percebe sofrimento já nos tambores de um regimento. Esse deslocamento, essa zombaria são uma consequência do emprego unitário de quando que, não causal, não impõe o esquema argumentativo.

\subsection{Emprego unitário de quando e semi-causalidade}

Três propriedades distinguem o emprego unitário de quando de um operador causal.

A primeira é que as palavras das orações gramaticais ligadas por um emprego unitário de quando aparecem como simples sinais do esquema argumentativo (nos termos da TBS, quando impõe somente que eles sejam caracterizantes). Um encadeamento não é, de fato, imediatamente legível, no sentido de que seu dado não implica o dado do esquema argumentativo que ele concretiza. O encadeamento argumentativo ela obtinha por genuflexão o direito de entrar e portanto avançava sob a nave alta entre a linha dupla de cadeiras pode ser entendido, já vimos, como concretizando o esquema TÉRMINO DE UM PREÂMBULO PARA ENTRAR COMO CATÓLICA DC ENTRAR COMO CATÓLICA ou como concretizando o esquema argumentativo TÉRMINO DE UM PREÂMBULO PARA ENTRAR DC ENTRAR - de modo que o exemplo (B) pode ser entendido de duas maneiras. É esse um fenômeno geral cuja observação é a razão do caráter duplo que define os conteúdos standards. Ora, um emprego unitário de quando especifica apenas o encadeamento evocado. Os termos das orações gramaticais são apenas índices do esquema argumentativo, manifestações circunstanciais da natureza profunda do acontecimento, termos da ordem causal.

A segunda propriedade do emprego unitário de quando é que ele autoriza a expressão de um conteúdo argumentativo, não mais standard, mas que conceitua, o que o afasta ainda, conforme vamos ver, da categoria dos operadores causais. Um conteúdo argumentativo é standard, acabo de lembrar, quando ele é constituído ao mesmo tempo por um esquema argumentativo e por um encadeamento que concretiza esse esquema. É o caso dos conteúdos argumentativos de todos os exemplos que analisamos até aqui. Mas certos enunciados, se eles evocam encadeamentos e apontam para um esquema argumentativo, não fazem, entretanto, alusão a um esquema argumentativo já construído. O locutor enumera sintomas, exemplos, indícios de uma situação geral, sem supor que essa situação geral tem um nome e que é conhecida independentemente dos exemplos. O movimento de pensamento é, então, o inverso daquele representado pelos conteúdos standards: o encadeamento não é o exemplo de um conceito conhecido, mas um primeiro passo para uma conceituação. Contrariamente aos conteúdos standards, que comportam ao mesmo tempo um encadeamento e um esquema argumentativo, o conteúdo comunicado comporta então somente encadeamentos, apontando para um esquema, e que servem para construir o esquema. $\mathrm{O}$ conteúdo da última frase do extrato seguinte é, assim, conceitualizante - a passagem aparece bem no início da parte II de "Um coração simples" e abre a narrativa da história de amor de Félicité e de Théodore:

Uma noite do mês de agosto (ela tinha então dezoito anos), eles a levaram à assembleia de Colleville. Imediatamente ela ficou atordoada, surpresa com o barulho dos violonistas, pelas luzes das árvores, a variedade das roupas, as rendas, as cruzes de ouro, essa multidão de pessoas pulando ao mesmo tempo. 
Notar-se-á a ausência de $e$ no final da enumeração. São evocados, um pouco desordenados, encadeamentos sem que o locutor suponha que a reação de Félicité tenha um nome e que o interpretante tenha de descobri-lo:

os violonistas faziam barulho portanto ela estava atordoada (ou estupefata)

luzes brilhavam nas árvores portanto ela estava atordoada (ou estupefata)

uma multidão de pessoas saltava ao mesmo tempo portanto ela estava atordoada (ou estupefata)

O conteúdo argumentativo é "conceitualizante". Dá-se o mesmo, eu já anunciava, com o conteúdo de certos empregos unitários de quando:

(22) O ideal de uma vida humana sempre foi para mim este: a poesia do amor e da felicidade no começo da vida; o trabalho, a guerra, a política, a filosofia, toda a parte ativa que pede a luta, o suor, o sangue, a coragem, o devotamento, ao meio; e enfim a noite, quando o dia termina, quando o barulho se extingue, quando as sombras descem, quando o repouso se aproxima, quando a tarefa está feita, uma segunda poesia; mas a poesia religiosa então, a poesia que se destaca inteiramente da terra e que aspira unicamente a Deus, como o canto de andorinha acima das nuvens. (LAMARTINE, primeiro prefácio das Méditations poétiques)

O locutor de (22) se mostra exprimindo, no decorrer do parágrafo, a razão do retorno à poesia. Seus primeiros empregos de quando dão lugar a conteúdos que conceituam, constituídos unicamente de encadeamentos:

\section{o dia termina portanto volta-se a ser poeta o barulho se extingue portanto volta-se a ser poeta as sombras descem portanto volta-se a ser poeta}

Depois o mas estabelece a natureza, religiosa, dessa segunda poesia de modo que é finalmente comunicado o conteúdo standard:

A tarefa está feita portanto celebra-se Deus compreendido como concretizando PROXIMIDADE DA MORTE DC POESIA RELIGIOSA.

Os primeiros conteúdos conceituam, os últimos são standards: os cinco empregos de quando são todos unitários. A conjunção impõe o encadeamento evocado, sem impor o esquema argumentativo expresso, nem mesmo dar instrução para descobri-lo.
Enfim, terceira e última propriedade do emprego unitário de quando, que o distingue de um operador causal, não impõe a natureza normativa ou transgressiva, do encadeamento. Vimos até aqui exemplos que evocam encadeamentos normativos, mas esses últimos podem ser transgressivos, quer a subordinada esteja no condicional, como no exemplo de Hugo, quer esteja no indicativo como nos exemplos de Flaubert:

(23) Quando até mesmo a abjeção pública cresceria/ A ponto de adorar o enganador execrável [...]/ Quando o proscrito deveria fugir de porta em porta $[\ldots] / \mathrm{Eu}$ não cederei! (HUGO, Les Châtiments)

(24) Desde então, Félicité pensou exclusivamente em seu sobrinho. Nos dias de sol, ela se atormentava com a sede; quando havia tempestade, ela temia, por ele, o raio. Ao ouvir o vento que roncava na chaminé e carregava as telhas, ela o via derrotado por essa mesma tempestade, no topo de um mastro quebrado, todo o corpo atrás, sob uma camada de espuma; ou então - lembranças da geografia em gravuras, - ele era devorado por selvagens, preso em um bosque por macacos, morria ao longo de uma praia deserta. E nunca ela falava de suas inquietações.

O exemplo (23) constrói encadeamentos transgressivos: "até mesmo se crescesse a abjeção pública a ponto de adorar o execrável enganador, eu não cederei e mesmo que o proscrito deva fugir de porta em porta, eu não cederei”.

E o exemplo (24), que descreve as inquietações de Félicité depois do engajamento de Victor de longa duração, comunica um conteúdo standard cujo esquema argumentativo é expresso por $X$ pensa exclusivamente em $Y$.

ASSUMIDO: Até mesmo se Victor não tinha relação com a tempestade, ela temia por ele o raio, entendido como concretizando NEG Y DIZ RESPEITO A Y PT X PENSA EM Y.

\section{Balanço}

Meu objetivo neste trabalho foi o de mostrar que os acontecimentos descritos em um emprego de quando anteposto são mais fortemente ligados do que por suas datas. Estudamos dois exemplos, o emprego coesivo, com o qual se relacionam, de modo geral, os exemplos que se considera marcarem a simultaneidade, e o emprego unitário, com o qual se relacionam ao mesmo tempo os exemplos que se diz marcarem a anterioridade e os exemplos que se considera instaurarem uma semicausalidade. Quando, num emprego coesivo, os dois 
acontecimentos constituem duas facetas de um mesmo Acontecimento: as duas orações comunicam dois conteúdos cujos esquemas argumentativos pertencem à significação de um termo. Quando, num emprego unitário, só um acontecimento é descrito: as duas orações são imbricadas em um único conteúdo, cujo esquema argumentativo é livre e cujo encadeamento liga, normativamente, ou transgressivamente, a oração subordinada e a oração principal. Essas observações não bastam, é claro, para uma descrição completa da conjunção quando - seria necessário estudar as restrições desses empregos. Elas visaram isolar as operações que, com fundamento no emprego de quando, permitem explicar a influência semântica da subordinada sobre a principal e as relações temporais que os fatos descritos mantêm, de acordo com a ótica referencial clássica.

Seria necessário ultrapassar a oposição da fusão e da imbricação e descrever todos os empregos antepostos de quando por meio de uma única operação, mais abstrata? Não creio e, mais do que tentar ultrapassar essa diversidade dos elos instaurados pelo emprego anteposto de quando, eu gostaria, ao contrário, essa será minha última observação, de pôr essa diversidade em paralelo com a de outro fenômeno, o da pressuposição. Pode-se de fato distinguir pelo menos dois tipos de enunciados com pressupostos - eu falava, em Carel (2011), de pressupostos "enunciativos" e de pressupostos "argumentativos":

(25) "a voz que me é cara deixou cair essas palavras", Lamartine, "Le Lac"

(26) “da hora fugitiva, apressemo-nos, aproveitemos!", Lamartine, "Le Lac"

O exemplo (25) introduz a célebre lamentação de Elvire sobre a fuga do tempo: o conteúdo pressuposto [a voz me é cara] é evocado, o conteúdo posto [a voz deixou cair essas palavas] é assumido, e, fundidos, esses dois conteúdos constituem um único Acontecimento. Ao inverso, o exemplo (26), que pertence à lamentação de Elvire, imbrica o pressuposto [a hora é fugidia] e o posto [é preciso aproveitar o tempo] em um único conteúdo [a hora é fugidia portanto é preciso aproveitála]. A alternância da fusão e da imbricação, presente nos empregos antepostos de quando, se encontra entre os enunciados com pressupostos. O parentesco de (25) e do emprego coesivo de quando não basta, é claro, para permitir a paráfrase de (25) por um emprego de quando: há, no emprego da conjunção, restrições que não são preenchidas pelo pressuposto de (25). Mas a unidade semântica de (25), como a de (A) se deve a uma fusão, e com isso se opõe à unidade semântica de (26), que, como a de (B) e (C) se deve, nela, a uma imbricação.
A natureza e a variedade dos empregos de quando deve ser procurada na natureza e na variedade dos fenômenos de pressuposição. Não há nada aí que diga respeito ao escoamento do tempo.

\section{Referências}

ANSCOMBRE, Jean-Claude. Le rôle du lexique dans la théorie des stéréotypes. Langages, Paris, n. 142, p. 57-76, 2001.

BENVENISTE, Émile. Problèmes de linguistique générale. Paris: Gallimard, 1966.

BENZITOUN, Christophe. Etude syntaxique de quand et avant que: entre rection, association et autonomie. Langages, Paris, n. 190, p. 51-65, 2013.

BORILLO, Andrée. Quelques remarques sur quand connecteur temporel. Langue française, Paris, v. 77, n. 1, p. 71-91, 1988.

CAREL, Marion. La polyphonie linguistique. Transposition: musique et sciences sociales, Paris, n. 1, p. 1-14, 2011. Disponible dans: $<\mathrm{http}: / /$ transposition.revues.org/365>.

CHAROLLES, Michel. Cohésion, cohérence et pertinence du discours. Travaux de linguistique, Paris, n. 29, p. 125-151, 1995.

DUCROT, Oswald. Dire et ne pas dire. Paris: Hermann, 1972.

DUCROT, Oswald. L'imparfait en français. Linguistische Berichte, Hamburg, v. 60, p. 1-23, 1979.

FLAUBERT, Gustave. Un coeur simple. Trois contes. Paris: Larousse, 2008.

FREGE, Gottlob. Sens et dénotation. Ecrits logiques et philosophiques. Paris: Seuil, 1971. p. 102-126.

GALATANU, Olga. Sémantique des possibiles argumentatifs et axiologisation discursive. In: BOUCHARD, Denis; ETLEVA, Vocaj; EVRARD, Ivan (Éds.). Représentation $d u$ sens linguistique. Paris: Duculot-De Boeck, 2007. p. 313-325.

HUGO, Victor. Les châtiments. Paris: Flammarion, 1999.

JACQUES, Lucien. Carnets de Moleskine. Paris: Gallimard, 2014.

LAMARTINE, Alphonse de. Première préface. Meditations poétiques. Paris: Édition des Souscripteurs, 1849. p. 1-26.

LAMARTINE, Alphonse de. Méditations poétiques. Paris: Gallimard, 2013.

LE DRAOULEC, Anne. De la subordination à la connexion temporale. Cahiers chronos, Amsterdam, n. 15, p. 39-62, 2006.

LESCANO, Alfredo. Deux (autres) maintenant: avec une application à l'analyse de La Jalousie de Robbe-Grillet. In: CAREL, Marion (Éd.). Argumentation et polyphonie: de Saint-Augustin à Robbe-Grillet. Paris: L'Harmattan, 2012. p. 145-188.

RIEGEL, Martin; RIOUL, René; PELLAT, Jean-Christophe. Grammaire méthodique du français. Paris: PUF, 2014.

VOGELEER, Svetlana. Quand inverse. Revue québecquoise de linguistique, Québec, v. 26, n. 1, p. 79-101, 1998.

Recebido: 30 de novembro de 2014

Aprovado: 27 de janeiro de 2015

Contato: marion.carel@ehess.fr 